\title{
Bosentan as a bridge to pulmonary endarterectomy for chronic thromboembolic pulmonary hypertension
}

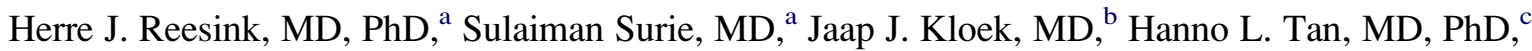 \\ Robert Tepaske, MD, PhD, ${ }^{\mathrm{d}}$ Peter F. Fedullo, MD, ${ }^{\mathrm{e}}$ and Paul Bresser, MD, PhD ${ }^{\mathrm{a}}$
}

\begin{abstract}
Objectives: In proximal chronic thromboembolic pulmonary hypertension, pulmonary endarterectomy is the treatment of first choice. In general, medical treatment before pulmonary endarterectomy is not indicated. However, selected "high-risk" patients might benefit by optimization of pulmonary hemodynamics. Moreover, in patients whose surgery is delayed owing to limited medical resources, pretreatment may prevent clinical deterioration. The primary objective of this study was to determine whether the dual endothelin- 1 antagonist bosentan improves pulmonary hemodynamics and functional capacity in patients with proximal chronic thromboembolic pulmonary hypertension waiting for pulmonary endarterectomy.
\end{abstract}

\begin{abstract}
Methods: We used an investigator-initiated, randomized, controlled single-blind study. Patients were randomized to receive bosentan $(n=13)$ or no bosentan $(n=12)$ for 16 weeks, next to "best standard of care." The primary end point was change in total pulmonary resistance. Secondary end points included changes in 6-minute walk distance, mean pulmonary artery pressure, and cardiac index.
\end{abstract}

Results: After 16 weeks, the mean differences in change from baseline between the groups were as follows: total pulmonary resistance 299 dynes $\cdot \mathrm{s} \cdot \mathrm{cm}^{-5}(P=.004), 6$-minute walk distance $33 \mathrm{~m}(P=.014)$, mean pulmonary artery pressure $11 \mathrm{~mm} \mathrm{Hg}(P=.005)$, and cardiac index $0.3 \mathrm{~L} \cdot \mathrm{min}^{-1} \cdot \mathrm{m}^{-2}(P=.08)$. Treatment with bosentan was safe. After pulmonary endarterectomy, 4 patients died (no-bosentan group: $\mathrm{n}=3$ ); the short-term in-hospital postoperative clinical course was similar in both groups of patients.

Conclusions: Patients with proximal chronic thromboembolic pulmonary hypertension may benefit hemodynamically and clinically from treatment with bosentan before pulmonary endarterectomy. Individual factors predictive of a beneficial response and whether this influences either morbidity or mortality associated with pulmonary endarterectomy remain to be established. (J Thorac Cardiovasc Surg 2010;139:85-91)

Chronic thromboembolic pulmonary hypertension $(\mathrm{CTEPH})$ results from incomplete resolution of the vascular obstruction caused by pulmonary thromboembolism. ${ }^{1}$ CTEPH is thought to develop in $1 \%$ to $4 \%$ of patients after acute pulmonary embolism. ${ }^{2,3}$ Pulmonary hypertension early in the course of the disease is considered the direct consequence of the loss of pulmonary vascular bed owing to vascular obstruction. However, if left untreated, a hemodynamic and symptomatic decline can be observed over time that appears to be related to the development of secondary arteriopathy in the small precapillary pulmonary vessels. ${ }^{1,4}$ As a consequence, prognosis in CTEPH is poor and proportional to the degree of pulmonary hypertension. ${ }^{5}$

\footnotetext{
From the Departments of Pulmonology, ${ }^{\mathrm{a}}$ Cardiothoracic Surgery, ${ }^{\mathrm{b}}$ Cardiology, ${ }^{\mathrm{c}}$ and Intensive Care Medicine ${ }^{\mathrm{d}}$ of the Academic Medical Center, University of Amsterdam, Amsterdam, The Netherlands, and the Division of Repiratory and Critical Care Medicine, ${ }^{\mathrm{e}}$ University of California San Diego, San Diego, Calif.

Disclosures: H.J.R. and S.S. received a nonrestricted research grant from Actelion Pharmaceuticals BV, Woerden, The Netherlands.

Received for publication Oct 20, 2008; revisions received March 23, 2009; accepted for publication March 29, 2009; available ahead of print June 1, 2009

Address for reprints: P. Bresser, MD, PhD, Academic Medical Center, University of Amsterdam, Department of Pulmonology, F5-144, PO Box 22700, 1100 DE Amsterdam, The Netherlands (E-mail: P.Bresser@amc.uva.nl).

$0022-5223 / \$ 36.00$

Copyright (c) 2010 by The American Association for Thoracic Surgery doi:10.1016/j.jtcvs.2009.03.053
}

Pulmonary endarterectomy (PEA) is the therapy of choice for patients with surgically accessible thrombi. ${ }^{1,6-10}$ In most patients, PEA can be performed with an acceptable mortality risk and results in clinical improvement and often nearnormalization of pulmonary hemodynamics. ${ }^{6,8}$ In the majority of patients with CTEPH, medical pretreatment before surgery is not deemed necessary. A significant proportion of patients with CTEPH who undergo PEA, however, are in hemodynamically unstable condition in the preoperative period to the point that risks from surgery in general are significantly increased. ${ }^{6-9}$ It can be hypothesized that if pulmonary hemodynamics and right ventricular function are optimized, these "high-risk" patients will benefit from medical treatment before PEA. ${ }^{11-13}$ Moreover, in patients whose operation is delayed owing to limited medical expertise or resources, medical treatment may prevent hemodynamic deterioration while the patient is awaiting PEA. ${ }^{11-13}$

Endothelin (ET)-1 is considered to play a role in the pathophysiology of the secondary arteriopathy observed in patients with CTEPH. ${ }^{14-16}$ In CTEPH patients with inoperable distal disease, in 3 uncontrolled, open-label studies, treatment with the dual ET-1 antagonist bosentan was associated with a significant hemodynamic improvement and an increase in the 6-minute walk distance (6-MWD). ${ }^{17-19}$ So far, no studies in surgically accessible, proximal CTEPH have been published. 


$$
\begin{aligned}
& \text { Abbreviations and Acronyms } \\
& \begin{aligned}
6-\mathrm{MWD} & =\text { six-minute walk distance } \\
\mathrm{BNP} & =\text { brain natriuretic peptide } \\
\mathrm{CI} & =\text { cardiac index } \\
\mathrm{CTEPH} & =\text { chronic thromboembolic pulmonary } \\
& \text { hypertension } \\
\text { ET-1 } & =\text { endothelin- } 1 \\
\text { mPAP } & =\text { mean pulmonary artery pressure } \\
\text { mRAP } & =\text { mean right atrial pressure } \\
\text { PEA } & =\text { pulmonary endarterectomy } \\
\text { TPR } & =\text { total pulmonary resistance }
\end{aligned}
\end{aligned}
$$

The primary aim of this investigator-initiated, randomized, controlled study was to assess whether treatment with bosentan for 16 weeks improves pulmonary hemodynamics and functional capacity in patients with proximal CTEPH who wait for PEA. As a secondary aim, we studied whether preoperative treatment with bosentan is safe and also assessed its relation with the short-term, in-hospital postoperative clinical course.

\section{PATIENTS AND METHODS \\ Patient Selection}

Consecutive patients with a diagnosis of symptomatic CTEPH, referred to the Academic Medical Center of the University of Amsterdam, were studied. Diagnosis of CTEPH and eligibility for PEA were established on the basis of previously reported procedures and criteria. ${ }^{20}$ Diagnosis and cardiopulmonary hemodynamics were determined by pulmonary angiography and right heart catheterization. As documented by echocardiography, left ventricular function was normal in all patients. Coronary angiography was performed in all patients older than 50 years of age and in patients older than 40 years of age if they had a history of smoking. All patients were treated for at least 3 months with oral anticoagulants before referral.

Inclusion criteria were mean pulmonary artery pressure (mPAP) greater than $25 \mathrm{~mm} \mathrm{Hg}$ at rest, baseline 6-MWD of 150 to $500 \mathrm{~m}$, and radiologic evidence of proximal, surgically accessible CTEPH. For ethical reasons, patients in New York Heart Association class IV/IV were excluded. Patients were also excluded if they had started or stopped any specific therapy for pulmonary arterial hypertension within 1 month before screening. The study was conducted according to the provisions of the Helsinki Declaration. The institutional ethical committee approved the protocol, and written informed consent was obtained from all patients.

\section{Study Design}

This was an investigator-initiated study, designed as a randomized, controlled, single-blind trial. Patients who were considered candidates for PEA and fulfilled the inclusion criteria were randomly assigned to receive conventional treatment ("best standard of care") with or without study medication (bosentan; Tracleer; Actelion Pharmaceuticals, Allschwil, Switzerland) for 16 weeks. Bosentan was prescribed according to standard guidelines: $62.5 \mathrm{mg}$ twice daily for 4 weeks, followed by 125 $\mathrm{mg}$ twice daily for 12 weeks. Patients were evaluated at baseline and after $4,8,12$, and 16 weeks of therapy. Safety was assessed on each visit by monitoring vital signs and adverse events. Liver function tests were monitored every 2 weeks for the first 8 weeks and every 4 weeks thereafter. Bosentan therapy was stopped in all patients on the day of the operation.

\section{Outcome Measures}

The primary end point was change from baseline in total pulmonary resistance (TPR) after 16 weeks of treatment. Secondary end points were change in 6-MWD, mPAP, cardiac index $(\mathrm{CI})$, and mean right atrial pressure (mRAP) and, in plasma, change in the level of brain natriuretic peptide (BNP) as a parameter of right ventricular function. ${ }^{21}$

Two sets of pulmonary hemodynamic measurements were determined by an observer who was blinded to the treatment regimen: at baseline and after 16 weeks of treatment (directly before PEA). Both catheterizations were performed under the same steady-state conditions; acute vasoreactivity testing using oxygen or vasoactive drugs was not performed at baseline. In addition, postoperative hemodynamic outcome was assessed on the first or second day after PEA, before removal of the Swan-Ganz catheter (Edwards LifeSciences, Irvine, Calif).

TPR was chosen to compare both groups, because pulmonary capillary wedge pressure measurements are often unreliable in the presence of proximal chronic thromboembolic disease, ${ }^{22}$ and insufflation of the Swan-Ganz catheter balloon within the pulmonary artery is contraindicated after PEA owing to the risk of suture line disruption.

\section{6-MWT}

The 6-MWT was performed in all patients according to the guidelines of the American Thoracic Society, ${ }^{23}$ as previously described. ${ }^{24}$ At least two practice walk tests were performed. All tests were supervised by a respiratory function technologist who was blinded to the treatment regimen.

\section{Laboratory Analysis}

From patients at rest for at least 15 minutes and in the supine position, blood was obtained from the brachiocephalic vein for plasma (ethylenediaminetetraacetic acid), centrifuged at $3000 \mathrm{rpm}$ for 10 minutes at $4^{\circ} \mathrm{C}$, and subsequently stored at $-80^{\circ} \mathrm{C}$ until analysis. BNP was determined by an immunoradiometric assay (Shionoria, Osaka, Japan), as previously described. ${ }^{25}$

\section{Surgical Procedure}

PEA was performed according to the protocol of the University of California San Diego. ${ }^{26} \mathrm{PEA}$ is performed via median sternotomy. After initiation of cardiopulmonary bypass, during deep hypothermia $\left(20^{\circ} \mathrm{C}\right)$, the right pulmonary artery is incised where it passes the aorta to the division of the lower lobe arteries. On the left, the incision extends from the main pulmonary artery to the origin of the left upper lobe branch. The organized thromboembolic material is fibrotic and adherent to the vessel wall. An endarterectomy plane is established between the intima and the fibrotic thromboembolic material. Subsequently, the obstructing material is grasped with a forceps, and distal circumferential dissection is performed with an aspirating dissector. Circulatory arrest is mandatory to ensure optimal visibility in the presence of usually copious retrograde blood flow from a hypertrophied bronchial circulation. The circulatory arrest period is limited to 20 minutes, with restoration of flow between each arrest.

\section{Statistical Analysis}

Data are expressed as mean \pm standard deviation. Differences between patient groups were analyzed with the 2 -sided unpaired Student $t$ test. To study the differences in individual patients between baseline and 16 weeks, we used the 2 -sided paired Student $t$ test. If indicated, $P$ values were corrected for multiple comparisons.

\section{RESULTS}

Between July 2003 and June 2006, 54 patients were considered eligible for PEA; 26 were included in the present study. Twenty-eight patients were excluded for the following reasons: 6-MWD greater than $500 \mathrm{~m}(\mathrm{n}=11)$; mPAP 
less than $25 \mathrm{~mm} \mathrm{Hg}(\mathrm{n}=5)$; lack of informed consent $(\mathrm{n}=$ 5); New York Heart Association class IV/IV $(\mathrm{n}=4)$; physically unable to perform 6-MWT $(n=2)$; and use of sildenafil at study entry $(n=1)$. Among the 26 included and subsequently randomized patients, 14 received bosentan and 12 received no bosentan. All but 1 patient completed the study. After 8 weeks of treatment, liver enzyme elevation (6 times the upper limit of normal) developed in 1 patient in the bosentan group. After bosentan treatment was stopped, the enzyme levels normalized. This patient was excluded from the analyses; 6-MWD had improved from 412 to $452 \mathrm{~m}$ after 8 weeks. No patient had renal impairment (serum creatinine $>120 \mu \mathrm{mol} / \mathrm{L}$ ).

Baseline clinical and hemodynamic characteristics are summarized in Table 1 . There were no statistically significant differences between the groups, except for mPAP, which was higher in the bosentan group. The use of oxygen and diuretics was similar in the two groups.

\section{Primary End Point}

Treatment with bosentan for 16 weeks was associated with a significant decrease in TPR (Figure 1). In contrast, in the no-bosentan group, TPR showed a small, but nonsignificant increase (Figure 1). The mean difference between the change in the groups was 299 dynes $\cdot \mathrm{s} \cdot \mathrm{cm}^{-5}(95 \%$ confidence interval: $105-493 ; P=.004$; Table 2).

\section{Secondary End Points}

After 16 weeks, in the bosentan group, 6-MWD had increased significantly, whereas 6-MWD in the no-bosentan group did not change $(348 \pm 86$ to $379 \pm 90 \mathrm{~m} ; P=$ .003 ; and $391 \pm 87$ to $388 \pm 95 \mathrm{~m} ; P=.79$; respectively). The mean difference between the change in 6-MWD was 33 m (95\% confidence interval: 7-59 m; $P=.01$; Figure 2).

Treatment with bosentan for 16 weeks was also associated with a significant decrease in MPAP and mRAP, whereas the $\mathrm{CI}$ tended to increase (Figure 1). In the no-bosentan group, after 16 weeks, no differences were observed. The levels of plasma BNP decreased in the bosentan group from $49 \pm 42$ to $31 \pm 26 \mathrm{pmol} \cdot \mathrm{L}^{-1}(P=.03)$. In the no-bosentan group, no change in BNP levels was observed $(47 \pm 54$ and $43 \pm$ $55 \mathrm{pmol} \cdot \mathrm{L}^{-1}$, respectively; $P=.57$ ). Between the two groups, the mean difference between the observed changes from baseline in mPAP was $11 \mathrm{~mm} \mathrm{Hg}(95 \%$ confidence interval: 4-19 mm Hg; $P=.005$; Table 2 ). The mean differences between the changes from baseline in mRAP, CI, and BNP, however, did not reach statistical significance (Table 2).

Between the two groups, neither the dosage of diuretics used at the end of the study nor the change in dosage of diuretics between baseline and the end of the study differed. Furthermore, a small loss of weight was observed in both groups (bosentan group $-0.55 \pm 2.9 \mathrm{~kg}$ and no-bosentan group $-0.02 \pm 2.5 \mathrm{~kg}$, respectively; $P=.6$ ).
TABLE 1. Clinical and hemodynamic characteristics of the two groups at baseline

\begin{tabular}{|c|c|c|}
\hline & Bosentan & No bosentan \\
\hline Subjects, $\mathrm{n}$ & 13 & 12 \\
\hline \multicolumn{3}{|l|}{ Demographics } \\
\hline Age, y & $67 \pm 8$ & $64 \pm 10$ \\
\hline Female, n $(\%)$ & $10(71 \%)$ & $8(66 \%)$ \\
\hline $\mathrm{BSA}, \mathrm{m}^{2}$ & $1.96 \pm 0.22$ & $1.89 \pm 0.19$ \\
\hline Height, cm & $167 \pm 9$ & $168 \pm 10$ \\
\hline Weight, kg & $84 \pm 18$ & $77 \pm 12$ \\
\hline \multicolumn{3}{|l|}{ Resting hemodynamics } \\
\hline mRAP, mm Hg & $14 \pm 6$ & $10 \pm 5$ \\
\hline mPAP, mm Hg & $52 \pm 7$ & $44 \pm 9^{*}$ \\
\hline PCPW, mm Hg (n) & $10 \pm 3(9)$ & $10 \pm 3(7)$ \\
\hline $\mathrm{CI}, \mathrm{L} \cdot \mathrm{min}^{-1} \cdot \mathrm{m}^{-2}$ & $2.1 \pm 0.3$ & $2.1 \pm 0.6$ \\
\hline TPR, dynes $\cdot \mathrm{s} \cdot \mathrm{cm}^{-5}$ & $1084 \pm 342$ & $988 \pm 415$ \\
\hline $\mathrm{SVO}_{2}, \%(\mathrm{n})$ & $57 \pm 8(12)$ & $58 \pm 11(11)$ \\
\hline 6-MWD, m & $353 \pm 84$ & $391 \pm 87$ \\
\hline \multicolumn{3}{|l|}{ Neurohormones } \\
\hline BNP, pmol/mL (n) & $44 \pm 45(12)$ & $44 \pm 52(11)$ \\
\hline \multicolumn{3}{|l|}{ Medication } \\
\hline Oxygen, $\mathrm{n}$ & 5 & 4 \\
\hline Diuretics & 13 & 11 \\
\hline Digoxin, $\mathrm{n}$ & 2 & 2 \\
\hline
\end{tabular}

Values are expressed as mean \pm standard deviation. 6- $M W D$, Six-minute walk distance; $B N P$, brain natriuretic peptide; $B S A$, body surface area; $C I$, cardiac index; $m P A P$, mean pulmonary artery pressure; $m R A P$, mean right atrial pressure; $P C W P$, pulmonary capillary wedge pressure; TPR, total pulmonary resistance; $\mathrm{SVO}_{2}$, mixed venous oxygen saturation. $* P<.05$.

\section{Outcome of PEA}

Four patients declined PEA. In 21 patients (11 bosentan, 10 no bosentan) PEA was performed. Four patients died during or after PEA. One patient in the bosentan group had a complicated postoperative course after hemodynamically successful PEA (post-PEA mPAP: $30 \mathrm{~mm} \mathrm{Hg}$ ). She died on the 10th day of sepsis of pulmonary origin with subsequent multiorgan failure. In the no-bosentan group, 3 patients died: 1 of peroperative massive alveolar hemorrhage and 2 of progressive right heart failure caused by persistent pulmonary hypertension on the third and 14th postoperative days, respectively. Postmortem examination was performed In the 3 patients who died in the no-bosentan group. In all patients, next to the central organized thrombi that were removed by PEA, in multiple subsegmental arteries, organized chronic emboli were demonstrated as well as abnormalities consistent with a secondary small-vessel arteriopathy. In the 20 patients in whom repeat hemodynamic studies could be obtained after the operation, PEA resulted in a significant hemodynamic improvement: mPAP decreased from $50 \pm 13$ to $30 \pm 11 \mathrm{~mm} \mathrm{Hg}$ $(P<.0001), \mathrm{CI}$ increased from $2.2 \pm 0.4$ to $2.4 \pm 0.5 \mathrm{~L}$. $\min ^{-1}(P=.09)$, and TPR decreased from $923 \pm 326$ to $529 \pm 251$ dynes $\cdot \mathrm{s} \cdot \mathrm{cm}^{-5}(P<.0001)$. Directly after PEA, persistent or residual pulmonary hypertension (mPAP $>25 \mathrm{~mm} \mathrm{Hg}$; range $26-55 \mathrm{~mm} \mathrm{Hg}$ ) was observed in 12 


\section{Bosentan}
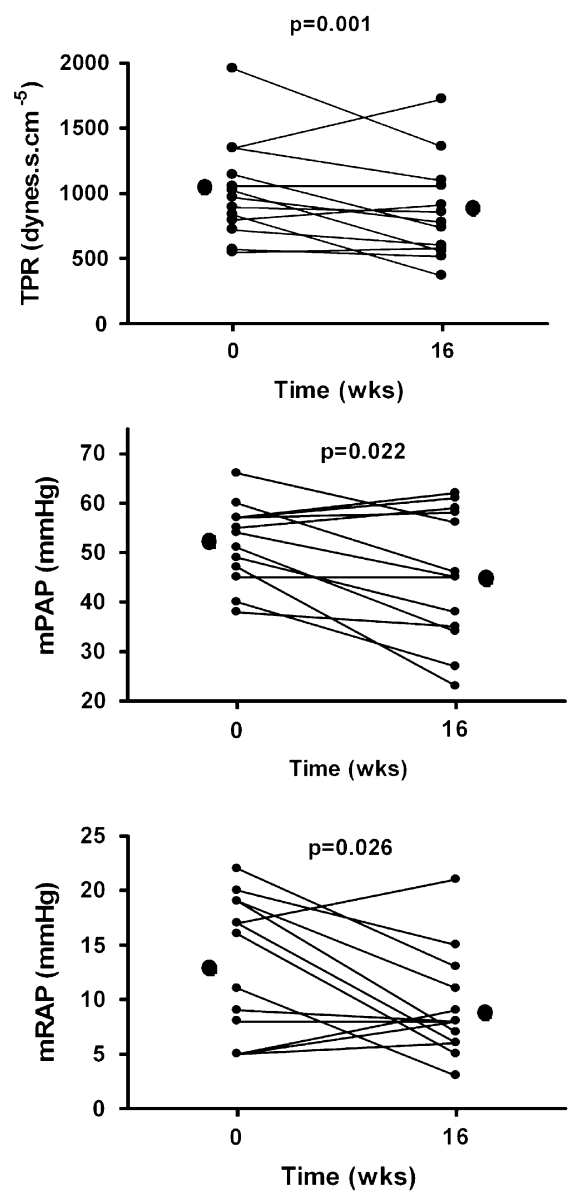

$\mathrm{p}=0.08$

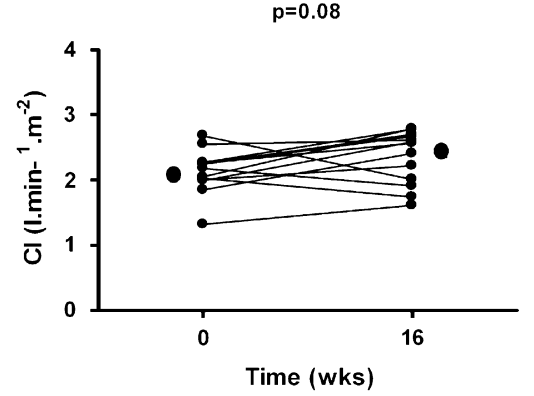

No-bosentan
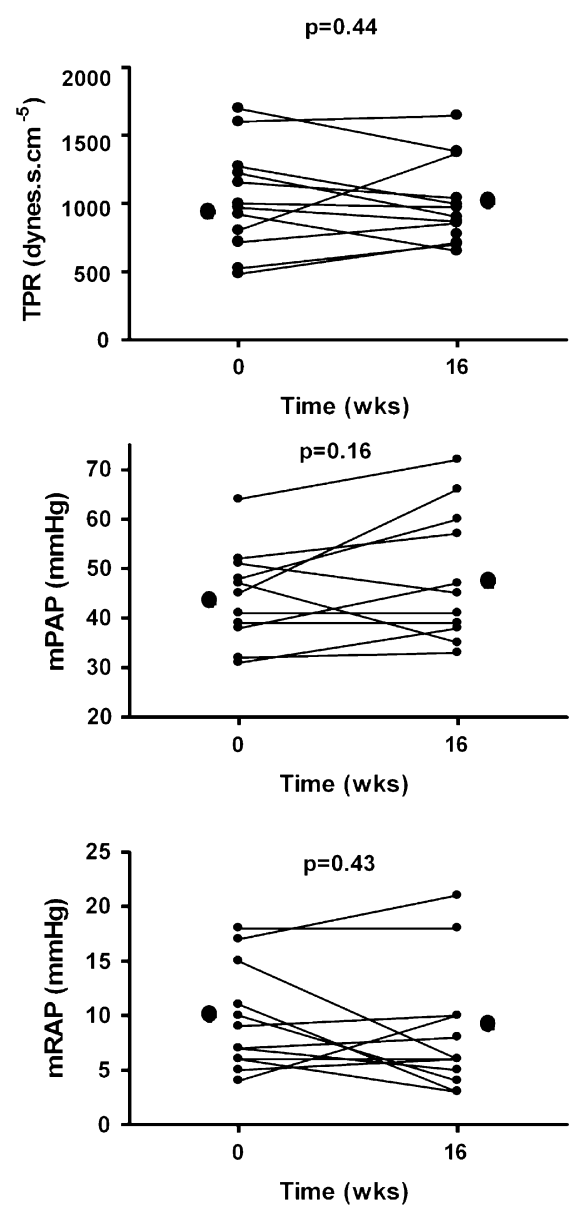

$\mathrm{p}=0.9$

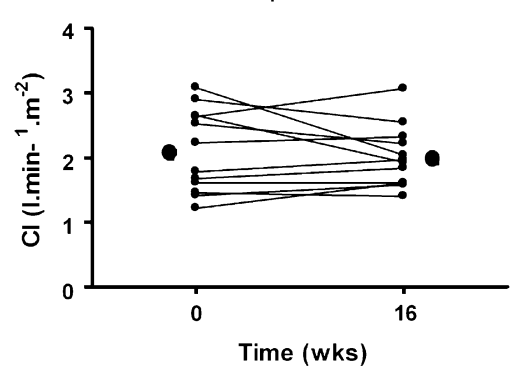

FIGURE 1. Individual hemodynamic characteristics at baseline $(0$ weeks $)$ and after 16 weeks in bosentan patients $(\mathrm{n}=13)$ and no-bosentan patients $(\mathrm{n}=$ 12). Within-group comparisons were made with the paired Student $t$ test. Black dots indicate mean group values. TPR, Total pulmonary resistance; $m P A P$, mean pulmonary artery pressure; $m R A P$, mean right atrial pressure; $C I$, cardiac index.

patients. Seven had mPAP greater than $30 \mathrm{~mm} \mathrm{Hg}, 2$ of whom died (mPAP 48 and $55 \mathrm{~mm} \mathrm{Hg}$, respectively). Preoperative and postoperative hemodynamic characteristics of both groups are summarized in Table 3; individual data on TPR are illustrated in Figure 3. Although compared with the nobosentan group, postoperative mean mPAP and TPR were lower in the bosentan group, these differences did not reach statistical significance $(P=.09$ and $P=.08$, respectively).
Postoperatively, no adverse hemodynamic effects of preoperative ET-1 blockade were observed. Moreover, in the patients who survived PEA, no statistically significant differences in short-term postoperative clinical course were observed between the bosentan and the no-bosentan groups with respect to the duration of stay in the intensive care unit (3.9 \pm 3.3 and $4.3 \pm 4.4$ days, respectively) or the duration of mechanical ventilation $(3.1 \pm 2.6$ and 
TABLE 2. Change from baseline after 16 weeks in primary and secondary study end points

\begin{tabular}{|c|c|c|c|c|}
\hline & Bosentan $(n=13)$ & No bosentan $(n=12)$ & Difference $(95 \%$ CI $)$ & $P$ value \\
\hline TPR, dynes $\cdot \mathrm{s} \cdot \mathrm{cm}^{-5}$ & $-237 \pm 198$ & $62 \pm 268$ & $299(105$ to 493$)$ & .004 \\
\hline mPAP, mm Hg & $-7 \pm 9$ & $5 \pm 9$ & $11(4$ to 19$)$ & .005 \\
\hline $\mathrm{CI}, \mathrm{L} \cdot \mathrm{min}^{-1} \cdot \mathrm{m}^{-2}$ & $+0.2 \pm 0.4$ & $-0.1 \pm 0.5$ & $0.3(-0.4$ to 0.7$)$ & .08 \\
\hline mRAP, mm Hg & $-5 \pm 6$ & $-1 \pm 5$ & $3.8(-8$ to 1$)$ & .16 \\
\hline $\mathrm{BNP}, \mathrm{pmol} \cdot \mathrm{L}^{-1}$ & $-18 \pm 24$ & $-4 \pm 21$ & $14(-33$ to 6$)$ & .16 \\
\hline
\end{tabular}

Values are expressed as mean \pm standard deviation. Differences between the treatment groups are expressed as mean change with $95 \%$ confidence intervals $(95 \% \mathrm{CI}$ ). Abbreviations are as in Table 1.

$3.4 \pm 4.4$ days, respectively). Reperfusion lung injury was observed once in both groups.

\section{DISCUSSION}

In this randomized, controlled study in patients with proximal CTEPH, preoperative treatment with the oral dual ET-1 receptor antagonist bosentan for 16 weeks was associated with a significant hemodynamic and functional improvement. Treatment with bosentan was safe and was not associated with a more complicated short-term postoperative clinical course. However, individual factors predictive of a beneficial response, and whether preoperative treatment with bosentan influences either morbidity or mortality associated with pulmonary endarterectomy in "high-risk" patients, remain to be established.

This is the first randomized, controlled study in patients with proximal CTEPH. The concept of introducing medical treatment as a "therapeutic bridge" between the CTEPH diagnosis and PEA was initially proposed for continuous intravenous epoprostenol. ${ }^{11,13,22}$ Although the pathogenesis of progression of disease in CTEPH, after the initial event, is still unclear, ET-1 is considered to play a role in the pathophysiology of the secondary arteriopathy. ${ }^{1,4,14,16}$ In a canine model of CTEPH, ${ }^{15}$ secondary pulmonary vascular remodeling has been demonstrated. In this model, increased ET-1 immunoreactivity was demonstrated in the thickened pulmonary arteries of the affected animals. Moreover, the development of vascular remodeling in this model could be attenuated by the administration of bosentan. In patients with CTEPH, circulating ET-1 levels correlate with hemodynamic severity of disease, ${ }^{16}$ and upregulation of the ET-B receptor gene in the hyperplastic media of pulmonary arterial biopsy tissue has been demonstrated. ${ }^{14}$ ET-B receptor activation on smooth muscle cells is considered to contribute to vasoconstriction ${ }^{27}$ and vascular remodeling. ${ }^{28}$ The reported effects of bosentan in patients with distal, inoperable CTEPH are also in support of a role for ET-1 in CTEPH. ${ }^{17-19}$ On the basis of the present data, blockade of the deleterious effects of ET-1 appears also of benefit in selected patients with proximal, operable CTEPH.

The definitive treatment for CTEPH is PEA. Primary medical therapy and pretreatment with medical therapy before PEA are not indicated in clinically stable patients who appear to have surgically accessible CTEPH that seems proportionate with the degree of pulmonary hypertension. However, selected patients with more complicated variants of CTEPH may benefit from preoperative medical treatment, specifically, those in whom a more complicated postoperative course is anticipated, that is, patients with signs of right heart failure or a severely increased pulmonary vascular resistance. ${ }^{6,8,9,11-13,29}$ In the present study, the condition of all but 1 patient treated with bosentan either improved or stabilized both hemodynamically and functionally. In particular, patients with increased right atrial pressure, indicating right heart failure, appeared to benefit. In our view, future studies should focus on better identification of high-risk patients who will truly benefit from medical treatment, as well as identification of those who might in fact benefit more from immediate surgery or referral to a highly experienced CTEPH center. Recently, we ${ }^{21}$ have reported on the potential usefulness of plasma BNP as a noninvasive parameter to identify patients with right heart dysfunction, known to be a risk factor for a more complicated postoperative course. ${ }^{6,8}$ On the basis of studies in inoperable CTEPH, acute hemodynamic responsiveness to vasoactive compounds like inhaled nitric oxide and sildenafil appears of little value to predict longer-term hemodynamic responsiveness on treatment. The individual hemodynamic improvement on

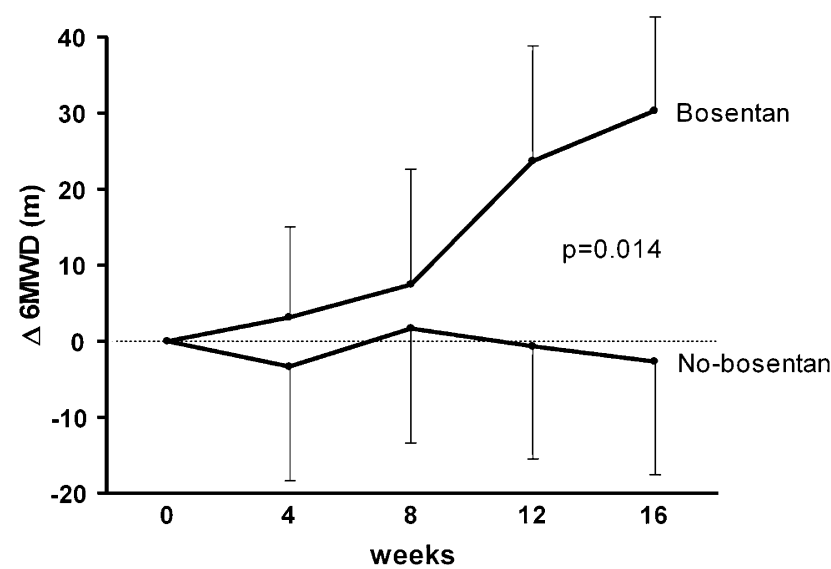

FIGURE 2. Effect of bosentan pretreatment on exercise capacity, expressed as the change (standard deviation) from baseline in 6-minute walk distance $(\triangle 6 M W D, \mathrm{~m})$ during the study in bosentan patients $(\mathrm{n}=$ 13) and no-bosentan patients $(\mathrm{n}=12)$. 
TABLE 3. Hemodynamic characteristics in patients with CTEPH who underwent PEA at inclusion in the study ( $t=0$ weeks), at the end of the study period (16 weeks), and postoperatively (Post-PEA)

\begin{tabular}{|c|c|c|c|c|c|}
\hline & I: 0 weeks & II: 16 weeks & III: Post-PEA & $P$ value I vs II & $P$ value II vs II \\
\hline \multicolumn{6}{|l|}{ Bosentan group $(\mathrm{n}=11)$} \\
\hline mPAP, $\mathrm{mm} \mathrm{Hg}$ & $52 \pm 8$ & $44 \pm 13$ & $25 \pm 16$ & .022 & .005 \\
\hline $\mathrm{CI}, \mathrm{L} \cdot \mathrm{min}^{-1} \cdot \mathrm{m}^{-2}$ & $2.1 \pm 0.4$ & $2.3 \pm 0.4$ & $2.5 \pm 0.5$ & NS & NS \\
\hline TPR, dynes $\cdot \mathrm{s} \cdot \mathrm{cm}^{-5}$ & $1099 \pm 353$ & $834 \pm 297$ & $432 \pm 134$ & .005 & .005 \\
\hline \multicolumn{6}{|l|}{ No-bosentan group $(n=9)$} \\
\hline mPAP, $\mathrm{mm} \mathrm{Hg}$ & $46 \pm 10$ & $49 \pm 13$ & $35 \pm 14$ & NS & .005 \\
\hline $\mathrm{CI}, \mathrm{L} \cdot \min ^{-1} \cdot \mathrm{m}^{-2}$ & $2.2 \pm 0.6$ & $2.0 \pm 0.3$ & $2.4 \pm 0.5$ & NS & NS \\
\hline TPR, dynes $\cdot \mathrm{s} \cdot \mathrm{cm}^{-5}$ & $979 \pm 440$ & $1029 \pm 345$ & $648 \pm 313$ & NS & .005 \\
\hline
\end{tabular}

Values are expressed as mean \pm standard deviation. Statistics were performed with the Student $t$ test with the Bonferroni correction for multiple comparisons. Abbreviations as in Table 1. CTEPH, Chronic thromboembolic pulmonary hypertension; PEA, pulmonary endarterectomy.

treatment with sildenafil for 3 months could not be predicted on the basis of the presence or absence of an acute hemodynamic responsiveness. ${ }^{30,31}$ The use of bosentan may be associated with some fluid retention. However, neither the use of diuretics nor the weight loss observed during the study period differed between the two groups of patients. In our view, future studies should focus on an objective means of better identifying high-risk patients. Currently, outcome prediction in terms of mortality and risk for a complicated postoperative course is a subjective one, requiring a substantial experiential base.

In the present study, treatment with bosentan was safe and was not associated with a more complicated short-term postoperative clinical course. In general, postoperative hemodynamic outcome in this series was good. After PEA, no adverse hemodynamic effects of ET-1 blockade were observed; patients pretreated with bosentan even tended to have a better hemodynamic outcome after PEA than did the no-bosentan group. In addition, the mean durations of stay in the intensive care unit and mechanical ventilation were similar in both groups. Four patients died, 2 of progressive right ventricular failure caused by severe postoperative persistent pulmonary hypertension. Persistent pulmonary hypertension after unsuccessful PEA is known to be associated with a highly increased mortality ${ }^{6,8}$ Forty-eight of 54 patients with CTEPH who were eligible for PEA underwent surgery, with an overall mortality of $8.3 \%$. At present, after more than 100 PEA procedures, the overall mortality in our center is around $8 \%$. Whether medical treatment before PEA in patients with CTEPH will result in a better survival cannot be determined on the basis of the present data. In the present study, bosentan was stopped immediately after the operation. In view of the effectiveness and safety observed in the present study, future studies should also focus on the role of bosentan in the postoperative phase in high-risk patients with CTEPH known to be at greater risk for hemodynamic instability and right heart failure after PEA.

A number of study limitations can be recognized. First, the study was open label, with the patients knowing whether they received bosentan or not. To minimize possible confounding by the open-label design, we chose TPR as the primary end point, and the cardiologist performing the catherization was blinded to the treatment regimen. In addition, the respiratory function technologist performing the 6-MWT was also blinded to medication status. However, patients who know they are included in an active treatment program are more likely to perceive improvement and therefore try harder to improve their 6-MWD. In view of the steady increase in 6-MWD observed during the course of the study, which is in line with previous observations in placebo-controlled trials in patients with pulmonary hypertension, ${ }^{32,33}$ this does not appears a likely explanation for the improvement observed. Second, patients were selected on the basis of 6-MWD. Recently, $\mathrm{we}^{24}$ demonstrated that 6-MWD correlates with severity of disease in patients with CTEPH. By including only
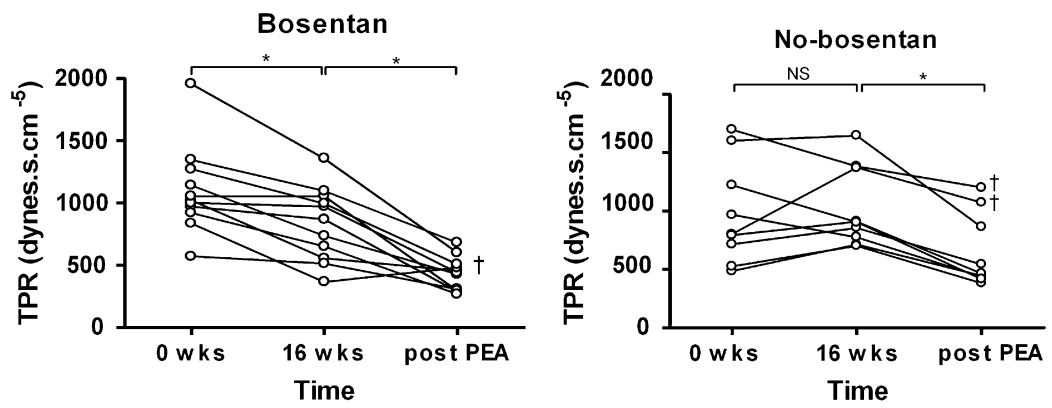

FIGURE 3. Total pulmonary resistance $(T P R)$ in patients operated on for chronic thromboembolic pulmonary hypertension at inclusion in the study $(0 \mathrm{wks})$, at the end of the study period $(16 \mathrm{wks})$, and postoperatively (post-PEA). Bosentan group $(\mathrm{n}=11)$; no-bosentan group $(\mathrm{n}=9)$. $P$ values were corrected with the Bonferroni correction for multiple comparisons. $* P<.05$. $\dagger$ Patients who died. $P E A$, Pulmonary endarterectomy. 
patients with 6-MWD less than $500 \mathrm{~m}$, we intended to select patients with more severe CTEPH and more compromised hemodynamics. However, we may also have excluded younger patients who walked relatively long distances, and we may have included older patients who had less compromised hemodynamics, but whose 6-MWD was in part limited by physical conditions unrelated to CTEPH. ${ }^{34}$

In conclusion, in the present study, treatment with bosentan was safe and associated with a significant hemodynamic and functional improvement. On the basis of our observations, we suggest that bosentan may be of use to optimize the treatment of selected patients with severe pulmonary hypertension at risk for postoperative mortality or a more complicated postoperative course.

Future studies should focus on a better identification of patients who will benefit most from medical pretreatment and assess whether preoperative treatment with bosentan influences either morbidity or mortality associated with pulmonary endarterectomy in these patients.

We thank Dr Jaring van der Zee for statistical advice and Dr Frans Boomsma from the Erasmus University, Rotterdam, The Netherlands, for the measurement of brain natriuretic peptide levels. Actelion Pharmaceutical BV, Woerden, The Netherlands, is acknowledged for providing the study medication.

\section{References}

1. Fedullo PF, Auger WR, Kerr KM, Rubin LJ. Chronic thromboembolic pulmonary hypertension. N Engl J Med. 2001;345:1465-72.

2. Becattini C, Agnelli G, Pesavento R, Silingardi M, Poggio R, Taliani MR, et al. Incidence of chronic thromboembolic pulmonary hypertension after a first episode of pulmonary embolism. Chest. 2006;130:172-5.

3. Pengo V, Lensing AW, Prins MH, Marchiori A, Davidson BL, Tiozzo F, et al. Incidence of chronic thromboembolic pulmonary hypertension after pulmonary embolism. N Engl J Med. 2004;350:2257-64.

4. Moser KM, Bloor CM. Pulmonary vascular lesions occurring in patients with chronic major vessel thromboembolic pulmonary hypertension. Chest. 1993;103:685-92.

5. Riedel M, Stanek V, Widimsky J, Prerovsky I. Longterm follow-up of patients with pulmonary thromboembolism. Late prognosis and evolution of hemodynamic and respiratory data. Chest. 1982;81:151-8.

6. Dartevelle P, Fadel E, Mussot S, Chapelier A, Herve P, de Perrot M, et al. Chronic thromboembolic pulmonary hypertension. Eur Respir J. 2004;23:637-48.

7. Hardziyenka M, Reesink HJ, Bouma BJ, de Bruin-Bon HA, Campian ME, Tanck MW, et al. A novel echocardiographic predictor of in-hospital mortality and mid-term haemodynamic improvement after pulmonary endarterectomy for chronic thrombo-embolic pulmonary hypertension. Eur Heart J. 2007;28:842-9.

8. Jamieson SW, Kapelanski DP, Sakakibara N, Manecke GR, Thistlethwaite PA, Kerr KM, et al. Pulmonary endarterectomy: experience and lessons learned in 1,500 cases. Ann Thorac Surg. 2003;76:1457-62.

9. Moser KM, Auger WR, Fedullo PF. Chronic major-vessel thromboembolic pulmonary hypertension. Circulation. 1990;81:1735-43.

10. Reesink HJ, Marcus JT, Tulevski II, Jamieson S, Kloek JJ, Vonk Noordegraaf A, et al. Reverse right ventricular remodeling after pulmonary endarterectomy in patients with chronic thromboembolic pulmonary hypertension: utility of magnetic resonance imaging to demonstrate restoration of the right ventricle. J Thorac Cardiovasc Surg. 2007; 133:58-64.

11. Bresser P, Fedullo PF, Auger WR, Channick RN, Robbins IM, Kerr KM, et al. Continuous intravenous epoprostenol for chronic thromboembolic pulmonary hypertension. Eur Respir J. 2004;23:595-600.
12. Bresser P, Pepke-Zaba J, Jais X, Humbert M, Hoeper MM. Medical therapies for chronic thromboembolic pulmonary hypertension: an evolving treatment paradigm. Proc Am Thorac Soc. 2006;3:594-600.

13. Nagaya N, Sasaki N, Ando M, Ogino H, Sakamaki F, Kyotani S, et al. Prostacyclin therapy before pulmonary thromboendarterectomy in patients with chronic thromboembolic pulmonary hypertension. Chest. 2003;123:338-43.

14. Bauer M, Wilkens H, Langer F, Schneider SO, Lausberg H, Schafers HJ. Selective upregulation of endothelin $\mathrm{B}$ receptor gene expression in severe pulmonary hypertension. Circulation. 2002;105:1034-6.

15. Kim H, Yung GL, Marsh JJ, Konopka RG, Pedersen CA, Chiles PG, et al. Endothelin mediates pulmonary vascular remodelling in a canine model of chronic embolic pulmonary hypertension. Eur Respir J. 2000;15:640-8.

16. Reesink HJ, Meijer RC, Lutter R, Boomsma F, Jansen HM, Kloek JJ, et al. Hemodynamic and clinical correlates of endothelin-1 in chronic thromboembolic pulmonary hypertension. Circ J. 2006;70:1058-63.

17. Bonderman D, Nowotny R, Skoro-Sajer N, Jakowitsch J, Adlbrecht C, Klepetko W, et al. Bosentan therapy for inoperable chronic thromboembolic pulmonary hypertension. Chest. 2005;128:2599-603.

18. Hoeper MM, Kramm T, Wilkens H, Schulze C, Schafers HJ, Welte T, et al Bosentan therapy for inoperable chronic thromboembolic pulmonary hypertension. Chest. 2005; 128:2363-7.

19. Hughes R, George P, Parameshwar J, Cafferty F, Dunning J, Morrell NW, et al. Bosentan in inoperable chronic thromboembolic pulmonary hypertension. Thorax. 2005;60:707.

20. Auger WR, Fedullo PF, Moser KM, Buchbinder M, Peterson KL. Chronic majorvessel thromboembolic pulmonary artery obstruction: appearance at angiography. Radiology. 1992;182:393-8.

21. Reesink HJ, Tulevski II, Marcus JT, Boomsma F, Kloek JJ, Vonk Noordengraaf A, et al. Brain natriuretic peptide as noninvasive marker of the severity of right ventricular dysfunction in chronic thromboembolic pulmonary hypertension. Ann Thorac Surg. 2007;84:537-43.

22. Kim NH. Assessment of operability in chronic thromboembolic pulmonary hypertension. Proc Am Thorac Soc. 2006;3:584-8.

23. ATS Committee on Proficiency Standards for Clinical Pulmonary Function Laboratories. ATS statement: guidelines for the six-minute walk test. Am J Respir Crit Care Med. 2002;166:111-7.

24. Reesink HJ, van der Plas MN, Verhey NE, van Steenwijk RP, Kloek JJ, Bresser P Six-minute walk distance as parameter of functional outcome after pulmonary endarterectomy for chronic thromboembolic pulmonary hypertension. $J$ Thorac Cardiovasc Surg. 2007;133:510-6.

25. Tulevski II, Hirsch A, Sanson BJ, Romkes H, van der Wall EE, van Veldhuisen DJ, et al. Increased brain natriuretic peptide as a marker for right ventricular dysfunction in acute pulmonary embolism. Thromb Haemost. 2001;86:1193-6.

26. Jamieson SW, Kapelanski DP. Pulmonary endarterectomy. Curr Probl Surg. 2000;37:165-252.

27. McCulloch KM, Docherty CC, Morecroft I, MacLean MR. EndothelinB receptormediated contraction in human pulmonary resistance arteries. $\mathrm{Br} J$ Pharmacol. 1996;119:1125-30.

28. Davie N, Haleen SJ, Upton PD, Polak JM, Yacoub MH, Morrell NW, et al. ET(A) and $\mathrm{ET}(\mathrm{B})$ receptors modulate the proliferation of human pulmonary artery smooth muscle cells. Am J Respir Crit Care Med. 2002;165:398-405.

29. Hartz RS, Byrne JG, Levitsky S, Park J, Rich S. Predictors of mortality in pulmonary thromboendarterectomy. Ann Thorac Surg. 1996;62:1255-9.

30. Reichenberger F, Voswinckel R, Enke B, Rutsch M, ElFechtali E, Schmehl T, et al. Long-term treatment with sildenafil in chronic thromboembolic pulmonary hypertension. Eur Respir J. 2007;30:922-7.

31. Suntharalingam J, Hughes RJ, Goldsmith K, Doughty N, George P, Tosher M, et al. Acute hemodynamic responses to inhaled nitric oxide and intravenous sildenafil in distal chronic thromboembolic pulmonary hypertension (CTEPH). Vascul Pharmacol. 2007;46:449-55.

32. Channick RN, Simonneau G, Sitbon O, Robbins IM, Frost A, Tapson VF, et al. Effects of the dual endothelin-receptor antagonist bosentan in patients with pulmonary hypertension: a randomised placebo-controlled study. Lancet. 2001; 358:1119-23.

33. Rubin LJ, Badesch DB, Barst RJ, Galie N, Black CM, Keogh A, et al. Bosentan therapy for pulmonary arterial hypertension. N Engl J Med. 2002;346: 896-903.

34. van der Plas MN, Duffels MG, Ponse D, Mulder BJ, Bresser P. Bosentan in mild pulmonary hypertension. Lancet. 2008;372:1730. 